\title{
Evaluation of a Sexuality Education Program: A Peer-Led HIV Prevention Intervention in Argentina
}

\author{
Brizuela $\mathrm{V}^{1}$, Aristegui $\mathrm{I}^{2}$ and Caceres $\mathrm{B}^{*_{3}}$
}

${ }^{1}$ Harvard T. H. Chan School of Public Health, 677 Huntington Avenue, Boston, MA, USA

${ }^{2}$ Fundacion Huesped \& Universidad de Palermo. Pje. Angel Peluffo 3932, (C1202ABB) Ciudad Autónoma de Buenos Aires, Argentina

${ }^{3}$ Fundacion Huesped. Pje. Angel Peluffo 3932, (C1202ABB) Ciudad Autónoma de Buenos Aires, Argentina

${ }^{*}$ Corresponding author: Caceres B, Fundacion Huesped. Pje. Angel Peluffo, 3932, (C1202ABB) Ciudad Autónoma de Buenos Aires, Argentina, Tel: + 5411 4981-7777, E-mail: betiana.caceres@huesped.org.ar

Citation: Brizuela V, Aristegui I, Caceres B (2017) Evaluation of a Sexuality Education Program: A Peer-Led HIV Prevention Intervention in Argentina. J Aids Hiv Infe 3(1): 101

Received Date: December 22, 2016 Accepted Date: March 30, 2017 Published Date: March 31, 2017

\begin{abstract}
Between 2010-2014, Fundacion Huesped and the Youth for Health Network implemented a sexuality education program, dance4life, in public schools in Argentina. A process evaluation was conducted in 2014 to assess the implementation of the program between 2010 and 2013, and make preliminary assessments of the impact on youth sexual and reproductive health.

A mixed-methods approach (qualitative-quantitative), using validated tools and frameworks, was applied through self-reported surveys, semi-structured interviews, and focus groups with students, peer educators, teachers, and staff. This was complemented by a desk review of past reports and program-related documents.

The program successfully trained over 2,000 "agents4change" (youth facilitators) over the four year period. The experiences reported were generally positive, highlighting peer-education as the most novel and attractive component for all the stakeholders. Educators and young people reported that the fact that this was a global program with international involvement was one of the positive aspects. $93 \%$ of respondents correctly identified modes of HIV transmission. Correct knowledge on contraceptive use was also high: $68 \%$ for the injectable; $99 \%$ for the condom. Positive changes in attitude were reported: $72 \%$ of respondents indicated great change in their respect for people living with HIV, and $60 \%$ in their capacity to openly talk about sexuality (60\%). $80 \%$ said they knew how to avoid unwanted sex.

Although the dance4life program had overall positive results, including increasing awareness of sexuality and confidence in decisions about sex, there are issues that would need to be addressed: e.g. project sustainability assuring lasting effects on school culture, and health system integration to improve health outcomes. Having baseline and monitoring data is critical to compare changes in young people's knowledge, attitudes, and practices about sex and HIV.
\end{abstract}

Keywords: HIV prevention; Sex education; Youth; Argentina; Reproductive health and rights

\section{Introduction}

According to UNAIDS, there are 36.7 million [34.0 million-39.8 million] people living with HIV globally (1). This number has been increasing since the early nineties, although the level at which it is increasing has declined since 2000; this is thought to be a product of a greater number of people on antiretroviral treatment (ART) who are now living longer. On the other hand, there has been a decrease in total new infections, from 3.2 million in 2000, to 2.1 million in 2015, as well as a decrease in new infections among children under 15: from 490,000 [430,000-560,000] in 2000 to 150,000 [110,000-190,000] in 2015 [1]. Of these new infections, $14 \%$ are among young men 15-24 years old, and 20\% are among young women 15-24 years old. There has also been a decline in AIDS-related deaths, from 1.5 million (1.3-1.8) in 2000, to 1.1 million (940,000-1.3) in 2015 and a significant increase in people on ART: from 770,000 in 2000 to 17 million in 2015.

In Argentina, an estimated 120,000 people were living with HIV in 2015 (an HIV rate of 13.5/100,000), and as with many other middle-income countries, there are great geographical differences [2]. The HIV rate in the Autonomous City of Buenos Aires (CABA) is estimated at 26.6, whereas it is estimated at 4.8 in the province of Santiago del Estero and 7.2 in Formosa [2]. Young people 15-24 years of age represent $16.6 \%$ of the total national population (if including 25-29 year olds, it raises to 24.3\%) [3]. Social determinants of health put young people at increased risk of infection, and poor outcomes [4,5].

Additionally, it is estimated that approximately $30 \%$ of people living with HIV in Argentina do not know their status, resulting in delayed access to treatment [6]. Among adolescent men 15-19 years old, the prevalence of HIV has been on the rise in recent 
years going from 3.9/100,000 in 2005 to 5.9/100,000 in 2013-2014 [2,7]. The number of infected women of the same age has gone down. The epidemic is concentrated in the main urban centers, such as Buenos Aires, where two-thirds of the people with HIV live. However, according to a 2013 nationally representative survey, close to $100 \%$ of the Argentine population state knowing about HIV-AIDS (98.6\% of women and $98.1 \%$ of men) [8].

Furthermore, knowledge on contraceptive methods and use is high, varying depending on the method. Although more than $80 \%$ of the respondents to the survey knew about contraceptive pills and condoms $(93.9 \%$ and $86.9 \%$ in women, and $81.7 \%$ and $95.1 \%$ in men, respectively), only $9.7 \%$ of women and $7.3 \%$ of men knew about emergency contraception, and $61.8 \%$ of women and $37.3 \%$ of men knew about the intra-uterine device (IUD) [8]. Despite this, reported contraceptive use at first sex is very high. On the other hand, $15.7 \%$ of all births are of adolescent mothers, and this rate increases significantly depending on the region: in the provinces of Formosa and Chaco (two of the poorest provinces in the country) this number climbs to 25\% [9]. This translates to a national fertility rate of 64.9/1,000, ranging from 33.1/1,000 in CABA and 89.5/1,000 in Formosa [9,10]. Approximately $12 \%$ of maternal deaths occur in women under 20 years old $[11,12]$.

dance4life is an international non-profit organization created in 2004 with a mission to end AIDS, unplanned pregnancies, and sexual violence among youth by making empowered sexual decisions. Their peer-led program incorporates sexual health and rights educational messages into an entertainment format, through dance and music to raise awareness, increase knowledge, and foster positive attitudes $[13,14]$. Their program is based on four components, each geared towards one of these different aspects: INSPIRE (by engaging young people), EDUCATE (through peer-led workshops), ACTIVATE (creating advocates and agents for change), and CELEBRATE (using dance and music to bring young people together across the globe). Through these four steps, dance4life seeks to establish a global movement of young people who will be better posed to curb the AIDS epidemic. This program was launched as a response to the Millennium Development Goals (MDGs), specifically MDG 6, aimed at combating HIV/AIDS, with the specific target 6.A "to have halted by 2015 and begun to reverse the spread of HIV/AIDS" [13,15].

Peer-led educational programs have been used in many different settings around the world. Although some of the findings of using this methodology for health education are mixed, especially with regards to long-term impact, there is some agreement that they present a benefit both to the young people participating in the activities, as well as among the young people leading them [16-18]. This is especially true for health education activities with regards to knowledge and self-efficacy related to sexuality and sexual health behaviors, and particularly with programs that include structured and systematic supervision [16,19]. Health behavior change is a complex problem that requires a multiplicity of actions aimed at increasing people's self-efficacy in their belief of being able to change attitudes and practices, as well as a vision that their actions will result in better health [20,21]. The use of activities that focus on strengthening those abilities stand a better chance at having successful results. Similarly, school-based interventions have been consistently used to reach a large proportion of young people, and SRH education is well suited for school settings [22].

dance4life has the following specific goals in Argentina:

1. To change the sexual and reproductive health behavior of young people in such that:

a. They feel empowered to decide whether to have sex or not;

b. They use condoms correctly and consistently;

c. They can discuss safer sex with their partners;

d. They seek help and support when needed (in educational settings and social organizations, among other places); and

e. They access health services in the settings where dance4life works.

2. To strengthen comprehensive sexuality education in schools.

3. To promote dialogue about sexual and reproductive health with families.

4. To increase the number of students who get tested for HIV.

5. To educate young people on sexual and reproductive rights.

Since 2005, Fundacion Huesped (FH) has been working with the Youth for Health Network (YHN) in projects that include peer education actions. Young people who were part of community based organizations, recognized as leaders among their peers and motivated towards community participation, were identified to become part of the network. Between 2010 and 2014 , FH and the YHN partnered to implement the dance4life program in approximately 20 public high schools in the Buenos Aires Metropolitan Area (AMBA). FH provided training and technical assistance, while YHN coordinated all the dance4life activities. The first year of implementation, a 5-day training on sexual and reproductive health and participatory methodologies was conducted by a team hired by dance4life international. This initial group coordinated the workshops throughout the year. Three of these young people acted as local coordinators with the aim of providing a closer follow-up, including support in the organization and coordination of workshops and organization of new trainings based on identified needs. In addition, monthly meetings of the YHN were held, with the participation of young people from different groups and geographical areas. During monthly meetings, peer-educators reported on their qualitative assessment of the implementation of the program (sharing potential facilitators and barriers), as well as on some quantitative indicators. However, these monitoring activities were not held or recorded in a systematic fashion.

Schools for the peer-education activities were selected based on proximity to the youth group organizations that conform the network, as well as on YHN's previous experiences in those schools. The workshops were planned jointly between FH and the 
YHN, and coordinated by the YHN members trained in sexual and reproductive health and rights, workshop facilitation, and group activities. The contents were framed from a gender and rights perspective, and included issues such as prevention of HIV and other sexually transmitted infections, rights of adolescents and people living with HIV, stereotypes about young people, sexuality, gender, and community participation.

For 2011-2014, a similar scheme was maintained, conducting initial trainings to incorporate new young people to the initiative and having regular meetings along the year. However, these activities and the local coordinators were financially and technically supported by $\mathrm{FH}$, and not dance4life. This resulted in a restricted length of trainings and size of the groups. In order to reach a similar amount of peer-educators, new locations were established. Another distinctive aspect, from the second year onwards, was the incorporation of young people who had participated in the youth-led workshops in their schools. This contributed to the team of educators' renewal, and to enrich the project with new participants' perspectives. The team of peer educators performed all activities on a voluntary basis, only receiving reimbursement for travel and meals during the activities.

Since 2009 dance4life has been gradually evaluating program implementation in different countries. This was the first time dance4life was evaluated in Argentina, and the first time FH conducted a formal evaluation of their peer-led educational programs. A process evaluation of the program was conducted in November-December 2014 to assess the results of the dance4life program implementation in Argentina between 2010 and 2013, to determine if the proposed activities had been completed, and whether predicted outcomes were reached. Additionally, the evaluation would make preliminary assessments about the impact of the program on the sexual and reproductive health of young people, their lives and their environments, and, ultimately make recommendations to improve the effectiveness and relevance of the program. An additional objective was to build capacity within $\mathrm{FH}$ in monitoring and evaluating tools and practices to assess other projects and programs.

\section{Materials and Methods}

\section{Evaluation type and design}

A process evaluation design was used to allow for an understanding of the peer-education program and how it was intended to work, and to consider how program characteristics and context may have impacted implementation [23]. Process evaluations are good at both providing input for formative and summative research. Formative research allows for a better understanding of why people behave the way they do, and allows for adjustments in program design and implementation, while summative research enables a judgment of how well a program was implemented [23,24].

A mixed methods, retrospective approach was used to evaluate the program [23,24]. This type of design was used to both get at the opinions and personal experiences with the program, while also assessing changes in certain attitudes, practices, and knowledge. Due to lack of baseline or systematic data collection throughout the duration of the program, ex post facto self-reported data by youth participants in the workshops was used. Because there was no control group during program implementation, data obtained from this evaluation were not compared with other youth educational programs or interventions. For comparison, results of this evaluation were compared with national and local statistics.

Quantitative data was obtained through a self-reported anonymous questionnaire that included questions about knowledge, attitudes, beliefs, and behaviors of young people who had participated in dance4life activities between March 2010 and December 2013. Data obtained from the questionnaires were analyzed using tools provided by STATA version 14.1 and Excel for descriptive statistics. Survey was completed through an online version (using SurveyMonkey) and an in-person/paper version.

Qualitative methods were used to obtain opinions, impressions, and beliefs about the program as well as detect potential issues with program implementation [25]. For this evaluation, semi-structured interviews and focus groups were used [26]. The former provides detailed information about the program from key stakeholders, helping understand strengths and/or weaknesses. The latter get at other information about perceptions, attitudes, experiences, and beliefs using the group dynamics to bring out information not otherwise obtained through individual conversations. Although qualitative data is not quantifiable or generalizable, they provide insight into details that may impact program implementation. For this evaluation, thirteen interviews and one focus group were conducted. Atlas.ti together with manual qualitative assessment were used to obtain main themes from the transcripts of interviews and focus groups [27]. This procedure was done with each of the interviews and focus group, and reiterated to reduce the number of topics and arrive at a few central themes. Unique themes emerged from each group of interviews and the focus group, and common themes were detected for the three groups of interviews and the focus group. The main themes selected were: peer education, dance4life implementation, activities/dynamics used, agents4change, knowledge prior to dance4life, continuation/ sustainability, difficulties and weaknesses, and linkage with healthcare services.

A desk review of past reports, and program related documentation was conducted. These were used to obtain data on the implementation of the program (number of programs executed, number of youth involved, etc.). Indicators of behavior, knowledge and attitudes related to HIV, sexual and reproductive health and rights were developed to allow analysis of the data obtained. See Annex 1 for the list of indicators and their respective descriptions. 


\section{Population and Sampling}

The target population of this evaluation was comprised of:

- Young people that participated in at least one of the dance4life activities between 2010 and 2013, for questionnaires and focus groups. Four of the questionnaires included in the analysis were from young people that participated in dance4life activities in 2014. These were included because activities had already been completed at the start of this evaluation, and there had been no modifications in the program design from prior year.

- Young people from the YHN who led dance4life activities in the schools, for interviews.

- Teachers and/or school principals of schools participating in dance4life, for interviews.

- Staff of FH who were involved in the implementation of the program, for interviews.

For the selection of people to interview a combination of random and convenience sampling techniques were used. Each school was assigned an identification number and these numbers were entered into www.random.org. Five numbers corresponding to five different schools were selected; individuals contacted for interviews in each of the schools were those who had been the main contact person between the school, FH, and the YHN during the implementation of dance4life. For the YHN peer-leaders, a list was created with all the names of those who had been leaders or coordinators for dance4life, and from that list, five individuals were randomly selected for the interviews. Because of difficulties in contacting many of them, a convenience sampling methodology was chosen to attain the desired number of five respondents. Final sample included four males and one female. The sample of people interviewed at FH included all three persons involved with dance4life activities.

For the survey, a 10\% threshold was established for the total number of people for whom FH had contact information available (range 1,000 - 1,300). The online questionnaire was publicly announced through FH, YHN, and dance4life Argentina social media accounts. People expressing interest in participating were contacted individually, and the survey was later emailed to them. Sample was complemented through direct messaging on social media, telephone calls, and email. Paper questionnaires were taken to schools within the catchment area of each of the network's youth organizations. A total of 100 questionnaires were completed.

For the focus groups, 20 students from different areas of the city and suburbs were contacted by FH and the YHN. These young people were selected based on available contact information and previous participation in at least one dance4life activity. A final sample of eight young people showed interest and participated.

\section{Tools developed}

To conduct the evaluation, various instruments were developed using validated tools and models, and based on existing literature and evidence.

\section{Questionnaire for participants in dance4life activities}

A specific questionnaire was designed for the dance4life program to collect basic demographic data and to learn about topics related to sexual and reproductive health and rights (SRHR) and HIV, as well as about attitudes and sexual behavior. The questionnaire took into account evaluations of dance4life in other countries, validated questionnaires concerning SRH and/or HIV, as well as the PAHO Global School-based Student Health Survey (GSHS) that had been validated for Argentina [28].

The questionnaire was developed in electronic format using the SurveyMonkey program and copies were also printed for delivery on paper (See Annex 2 for the complete questionnaire).

\section{Semi-structured interview guide}

Three interview guides were developed: one for use among school staff (teachers and principals), another for use with peer youth leaders (YHN), and one for use with FH.

The guides sought to explore personal experiences with the program, barriers and strengths, recommendations for improvement, as well as the perception of changes in attitude in the schools among health promoters and school managers. The interviews aimed at getting at positive, negative, or unexpected outcomes of the program among participating youth. (See Annex 3 for the guides used).

\section{Focus group guide}

The guide designed for this evaluation had the objective of obtaining information about the different stages of the dance4life program (INSPIRE, EDUCATE, ACTIVATE, and CELEBRATE), changes in attitude, knowledge, and practice, and experiences with program implementation at schools, as well as the level of self-esteem and self-efficacy among agents4change. (See Annex 3 for the focus group guide).

\section{Activities Conducted}

- A quantitative survey of 100 young people who participated in dance4life activities. 
- Five semi-structured interviews of teachers and principals from five schools (one from each) that participated in the dance4life activities.

- Five semi-structured interviews with YHN peer-educators.

- Three semi-structured interviews with staff involved with dance4life from FH.

- One focus group with eight young people who participated in some of the dance4life activities.

- A literature review of past reports, analysis of questionnaires and interviews.

The activities for the evaluation were coordinated by an external evaluator (VB), with collaboration from FH and YHN staff members to address capacity building within FH. Database for data collection was created by the external evaluator. The staff of FH oversaw the distribution and collection of the questionnaires, and supervised data entry staff.

Before distributing the questionnaire, it was validated with six young participants of the YHN who had been involved with the dance4life activities. Their comments and feedback were considered -including usability of the tool, question comprehension, internal validity, and technical problems with the online tool. This step was complemented with a telephone conversation with one of the six young participants who had been involved in the online validation, delving deeper into the understanding of the questions, the objective of the survey, and difficulties which might have arisen. All the comments were incorporated into the final version of the questionnaire.

\section{Results}

\section{Quantitative results}

Participation: Between 2010 and 2013, a total of 105 activities of the INSPIRE step were completed in 97 schools ${ }^{1}$ and ten informal education organizations. A total of 7,607 students participated in activities related to this first step in the four years of program implementation under review. 96 EDUCATE programs were conducted at schools, involving a total of 3,267 students trained as agents4change ${ }^{2} .977$ agents4change participated in the last step of the program. Trends in participation per year are included in Figure 1.

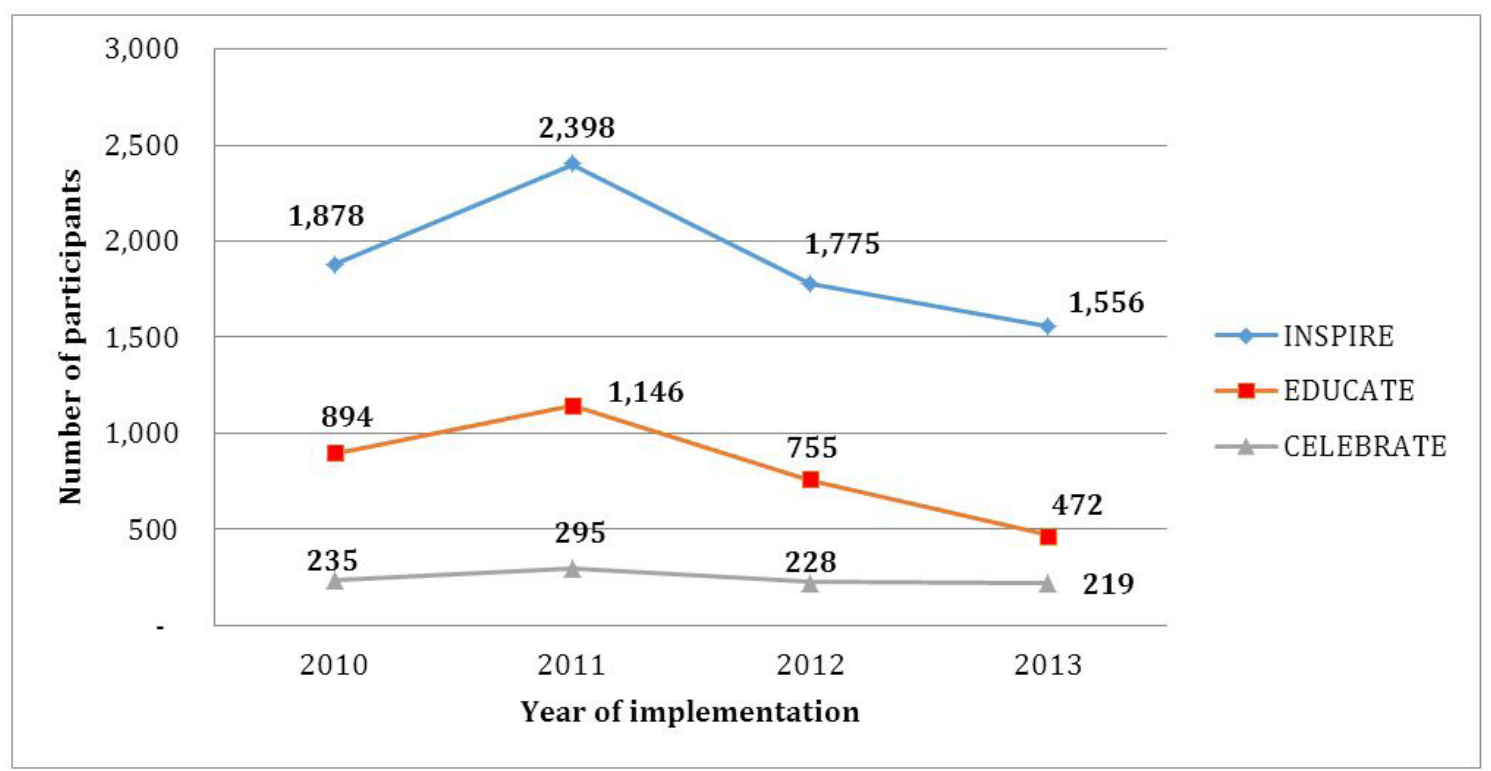

Figure 1: Trends in participation in the INSPIRE, EDUCATE, and CELEBRATE steps, by year for the period 2010-2013

Although the number of participants in the steps INSPIRE and EDUCATE shows a decreasing trend starting in 2011 -after an increase between 2010 and 2011 - these data appear to be consistent with FH's statement highlighted in the interviews: the need to narrow their focus and concentrate on a smaller number of schools to ensure continuity of the program, and a follow-up of those young people interested. The number of agents4change present during the CELEBRATE stage was relatively constant during the four years under review.

Knowledge, attitudes, and practice: A total of 100 questionnaires were completed, 36 were collected online using the SurveyMonkey program and the remaining 64 were gathered on paper in three schools: two in AMBA, and the other in CABA. Characteristics of the sample are included in Table 1.

${ }^{1}$ Due to how public schools are administrated in Argentina, where there are usually three school shifts with separate student populations within a single school (i.e. morning, afternoon, and evening shifts). Each shift was counted as a separate school/activity.

${ }^{2}$ dance4life refers to agent4change as those young people who have participated in the initial three activities: INSPIRE, EDUCATE and ACTIVATE. For the purposes of this evaluation, and in following the model proposed by FH, the term agent4change was used for everyone who participated in the EDUCATE step, because of the involvement that the implementation of the program in Argentina demands, and because there are scarce and incomplete records of the ACTIVATE activities. 


\begin{tabular}{|c|c|}
\hline Characteristics of the sample & $\%$ \\
\hline \multicolumn{2}{|l|}{ Gender } \\
\hline Female & 48 \\
\hline Male & 48 \\
\hline Other & 1 \\
\hline Missing & 3 \\
\hline Mean age (range 14-27) & 17 \\
\hline \multicolumn{2}{|l|}{ Education (current grade) } \\
\hline 7 th grade (1st year secondary school) & 1 \\
\hline 8th grade (2nd year secondary school) & 31 \\
\hline 9th grade (3rd year secondary school) & 5 \\
\hline 10th grade (4th year secondary school) & 7 \\
\hline 11 th grade (5th year secondary school) & 26 \\
\hline 12th grade (6th year secondary school) & 7 \\
\hline Graduated & 18 \\
\hline Dropped out & 1 \\
\hline Missing & 4 \\
\hline \multicolumn{2}{|l|}{$\begin{array}{l}\text { Year in which they participated in the } \\
\text { dance4life intervention }\end{array}$} \\
\hline 2010 & 14 \\
\hline 2011 & 19 \\
\hline 2012 & 19 \\
\hline 2013 & 38 \\
\hline $2014^{*}$ & 4 \\
\hline
\end{tabular}

*these answers were allowed since the program had not been modified at all between 2013 and 2014 , and the program had already ended in the school where these respondents were students Table 1: Demographic data on sample $(\mathrm{N}=100)$

The respondents had, on average, a very high level of knowledge on HIV and contraception, including modes of HIV transmission, which fluids can transmit the virus, and contraceptive methods (Figures 2 and 3). Although 91\% of respondents could remember talking about adolescent sexual and reproductive rights, only $50 \%$ knew that a sexual health and responsible reproduction law exists, compared with 66\% knowing about the AIDS law, and $85 \%$ about the comprehensive sexuality education law. On the other hand, 38\% indicated not knowing about the first law, 27\% about the second one, and 9\% about the last one. Sixty-five percent of respondents mentioned they "really liked" the dance4life activities and 19\% said they "somewhat liked" them, while only $4 \%$ answered that they had "not liked" them at all. Changes in attitude with respect to sexuality were also high, especially with regards to respect towards people living with HIV (Figure 4).

Sexual and reproductive behavior: Sixty-six percent of respondents reported having had sex, $25 \%$ said they hadn't, $4 \%$ preferred not to answer, and there was 5\% unanswered. The average age at first sex was 15 years (range 10-20 years) and very similar for both genders. The majority had their first experience with a boyfriend/girlfriend. Among those who were not sexually active, the main reasons mentioned for not having sex yet were: wanting to wait until they were older or married (41\%), because they were only recently involved in a relationship (30\%), and because they hadn't had a chance yet (22\%). This question allowed for multiple responses.

Seventy-three percent of respondents said they had safe sex in their first sexual encounter and $88 \%$ responded having had safe sex in their most recent sexual relationship; $89 \%$ responded they used contraception when having sex always or most of the time. Most respondents regularly used condoms (83\%), followed by those who used birth control pills (48\%). There were 5\% of respondents who said they did not use protection because they wanted to become pregnant, and another $6 \%$ said they were not having safe sex but not seeking pregnancy either. Among those who had reported having had sex, $8 \%$ had ever been pregnant (or gotten their partner pregnant) and the current average age of these respondents was 19 years. (Annex 4).

Of the total participants, only $19 \%$ had gotten tested for HIV; $75 \%$ said they had not. There were 9 people who said they had gotten tested before the dance4life program went to their school and 10 had it done after. $52 \%$ had gotten tested at a public hospital, while the rest of the responses were distributed evenly between getting tested at a community health center, at a private clinic, or at their doctor's.

Only $41 \%$ of the respondents had ever had any health visit about their sexual and reproductive health; of these, $63 \%$ were women. The places the young people most frequently mentioned of where to get support on questions related to their sexuality were a health center and a public hospital. 


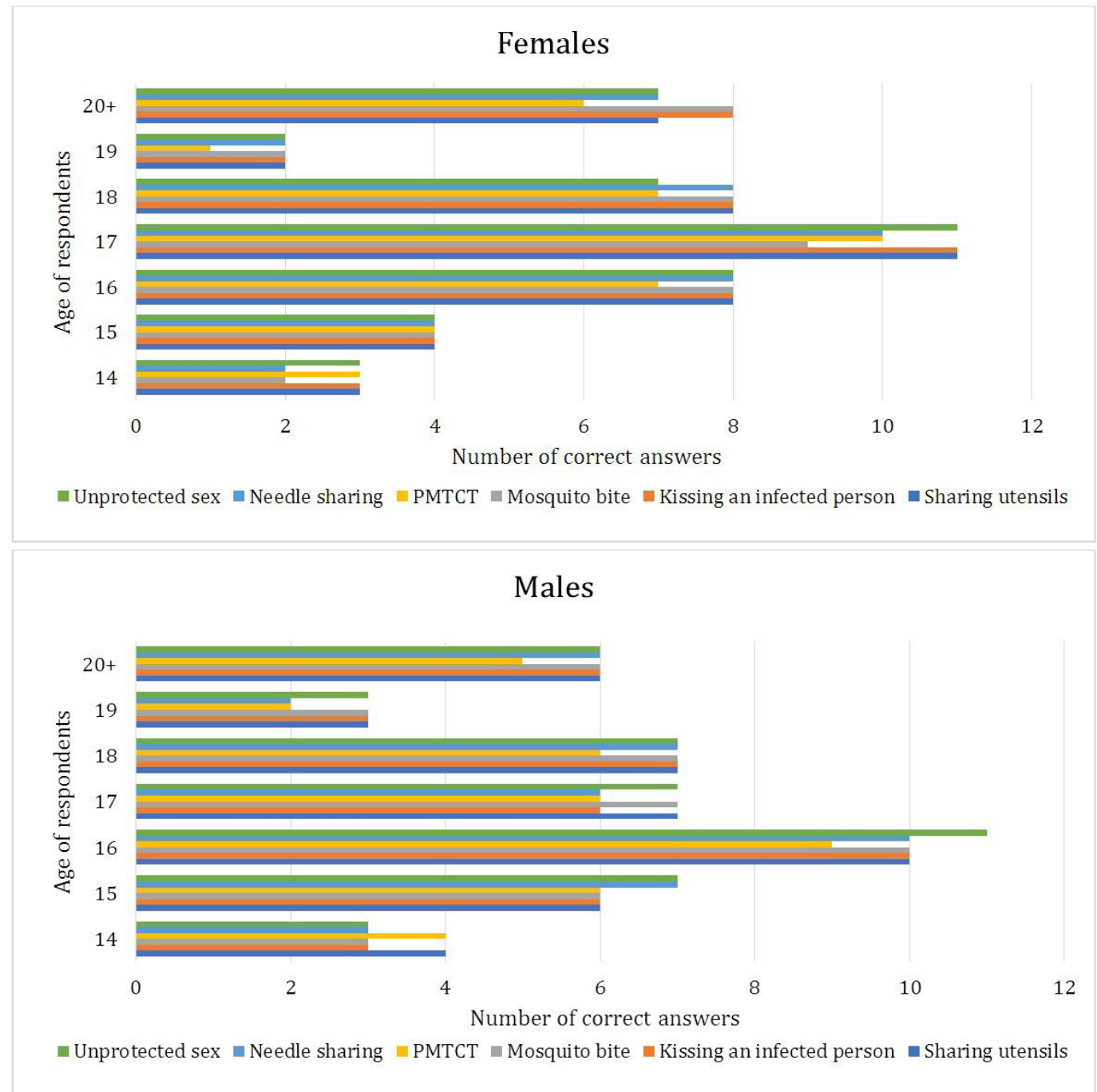

PMTCT: prevention of mother-to-child transmission

Note: for unprotected sex, needle sharing, and PMTCT, the correct answer was YES, whereas for mosquito bite, kissing an infected person, and sharing utensils, the correct answer was NO

Figure 2: Number of correct answers relating to knowledge about HIV transmission, by age and sex $\left(\mathrm{N}=96^{*}\right)$

$\left.{ }^{*}\right)$ These graphs only include answers for males $(\mathrm{N}=48)$ and females $(\mathrm{N}=48)$; responses by other genders not included



Figure 3: Correct knowledge (percentage) about contraceptive methods, by gender $\left(\mathrm{N}=96^{*}\right)$

$\left({ }^{*}\right)$ These graphs only include answers for males $(\mathrm{N}=48)$ and females $(\mathrm{N}=48)$; responses by other genders not included 


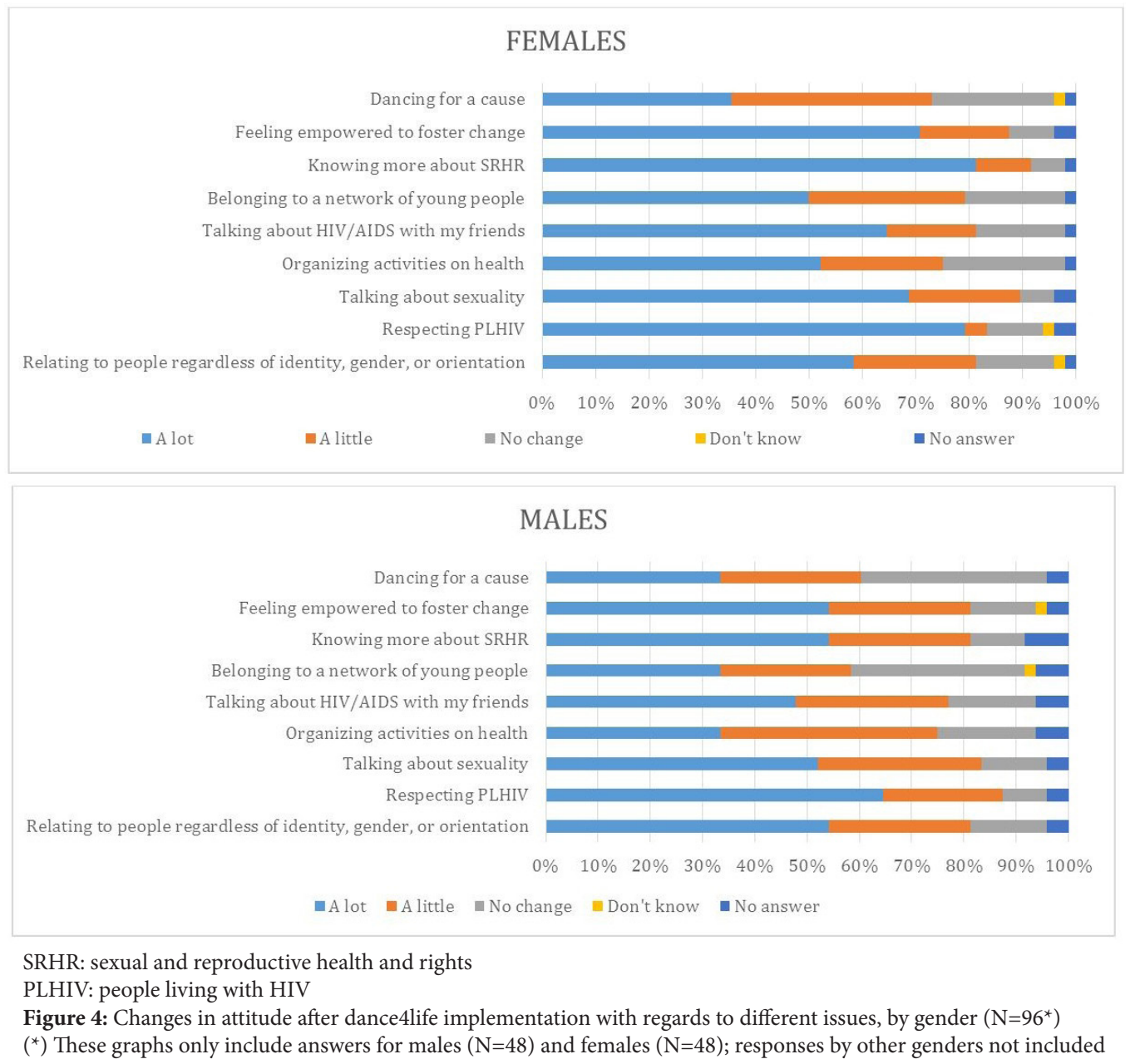

\section{Qualitative Results}

Semi-structured interviews: Throughout the 13 interviews, recurring themes were identified, especially regarding the impact of having young people coordinate and facilitate workshops, the effects of having a program like dance4life at schools in AMBA, the training of agents4change, and the crucial points for the sustainability of the program, among others.

Almost all respondents felt that having young people leading and coordinating the dance4life activities was a positive aspect of the program, and in fact, some even considered it the strongest point.

"I think it was valuable for the kids to have a space where they could focus on a topic from a specific viewpoint, with people who are not a part of the school and, therefore, they can talk openly to, while at the same time because of their closeness in age, since they are young people too, they could address the topics from their daily life sharing their experiences together." (Teacher)

"What also makes students want to be a part of dance4life is that it is led by people of their same age, they are not grown-ups, you know, where they say 'no, this guy is so old, what does he know'." (YHN member).

"For me the strongest point is the youth participation in the program. Without a doubt, it is a strong point, in the coordination, in the project design." (FH staff).

Interestingly, one of the aspects that many of the respondents highlighted was related to the language used by the peer leaders, together with their age.

"... the approach of having peers talking to the young people is a good strategy because the way of communicating is different. At times, also the language. We get to them in a different way." (YHN member)

"Did age have an effect? Maybe, but what did have an impact was having used the same vocabulary that they use." (Teacher).

On the other hand, there was a strong recognition of the positive effect that the YHN had on young people, especially as reported by the youth of the YHN and the staff of FH. Some mentioned that belonging to a group was positive, also strengthening their roles and confidence as agents4change in their own communities. 
"I like it; it makes me feel really good. I can go to schools, help people, and answer their questions. That's what I like (about it), and what I like about being an agent4change." (YHN member)

"For me, there is something very beautiful about the youth from the network, especially among the youngest or newest who you see become more confident from just attending a workshop silently because they don't dare to do anything, until you then see them coordinating a workshop in front of all the kids." (FH staff).

Several people mentioned the paucity of information that the young people in the schools had prior to the presence of dance4life. There was general agreement among respondents that the use of games, activities, and audiovisual material, among other elements, were strong points of dance4life. There was also agreement among some respondents about the positive aspect of having a program of international scope.

"They actually had fun (...) so the kids learned a lot while playing. So they felt very enthusiastic, and they told the others about it." (Teacher).

"It's great when you leave and the teacher tells you 'I really liked how you did the workshop' or 'I liked the strategy you used'. And it is good for that to happen, too. And often times this happens with the principals. The principals also get very excited (and ask) for more activities." (FH staff).

"(As students) we didn't know much. Maybe we didn't pay much attention to that. It was not taught in the school. We were in "health and adolescence" classes learning about the reproductive system. (...) Now, the students don't have just basic information. They know something (more)." (YHN member).

"From my point of view it was very innovative, especially how it ended and also that it had an international aspect." (Teacher)

As for the weaknesses or difficulties with the program, there were different salient themes, such as: logistical problems (lack of adequate space for workshops, number of participants, and coordination with the schools), commitment of principals and authorities, and some specific issues about the activities.

"At times, there are difficulties but they are external to us, like the physical space that sometimes is not adequate. Many times we had to go to many places in winter and in the cold. The schools' infrastructure posed an important issue." (FH staff).

"When I was here, (during) my management, I never heard of any activity that had been done." (Principal).

"Maybe, because of the number of people participating at that time, it could get a bit chaotic. If I remember correctly, the methodology was to have a first meeting for all the youth together and then work in smaller groups." (Teacher).

"There are drawbacks like... the problem of negotiating topics and materials that are to be used." (FH staff).

About the difficulties with specific content or with implementation of the ACTIVATE step, there was agreement that there was some student resistance to the topic of SRHR and in implementing the ACTIVATE step.

"When you talk about laws it is somewhat boring (...). But that part is the densest part of the EDUCATE, but we have to explain it to them, share information to get them to know, because if not..." (YHN member).

"There are topics to which they don't pay much attention, when we speak of rights, or begin to mention them." (YHN member).

"Mostly, when they have to show something (ACTIVATE), that we give something for everyone to do and they have to bring things and prepare them. Make posters ... and it is somewhat complicated. They get lazy." (YHN member)

"And that thing about trying to talk with others. They had to go to a public plaza; I think they agreed to go to a square. That failed." (Teacher).

"ACTIVATE usually is left up in the air "(FH staff).

Lastly, there were different opinions about the presence or absence of teachers in the classrooms during the workshops. The young people though it critical not to have the teachers present, whereas FH staff stressed the importance of having teachers remain in the classroom during dance4life activities.

"I think for the young people, it makes them feel at ease, that they don't get with the teachers (present). There have been workshops with teachers and the youth didn't feel free to speak (...)." (YHN member). 
"The teachers can be there, but this is how (...) Our idea is to go into the classroom so that later a teacher can follow up on these topics, so it's much better if the teacher is there to know what we are working on and how we are doing it. (FH staff).

"For me, the other thing that is still a little weak is the issue of having teachers remain in the classroom. We think they have to be there because of the issue of responsibility (...) but then in reality, they take advantage and go to do other things or leave ... many times with the pretext 'if I stay the kids get intimidated'." (FH staff).

The activities related with the CELEBRATE step were referred to in almost every interview as a positive event and one of the strengths of the program: "CELEBRATE (is the activity they like the most)". One of the reasons identified for which this was so valued was the possibility of socializing with other youth and the network they build on these occasions.

What came through from the interviews was that sustainability of the program was rather weak. The interviews with teachers and principals revealed that as soon as dance4life stopped going to the school, there was very little done to replace or continue with some of the activities initiated, despite the perceived positive experience with the program and the innovative proposal.

"Afterwards it was like the ties were cut a bit. I do not know if the young man stopped working, or if FH stopped doing the activity, I don't know." (Teacher).

"It didn't continue (...) And everyone blames me, because I retired. And others blame the new principal." (Principal).

"Because, (FH) was actually there like for three years. Then they stopped coming and it was like nothing had happened. There was no comment like 'hey, the Fundacion didn't come any more, what a pity'. Nothing, nobody cared. So, there was no feeling that FH needed to continue coming to the school." (Teacher).

This result is especially important to consider given that many of the people interviewed mentioned that before dance4life came to their schools, there was no comprehensive sex education being taught in the classrooms, despite the national mandate to do so.

"We did begin working together with the gynecologist from the health center that set up a kind workshop in the school where she would answer questions once a week. She didn't go to the classrooms. (...) The school didn't interfere with this either." (Teacher).

"It was talked about in the Biology class if I remember correctly (...). I remember one day they handed out condoms too. Yes, they talked about it, but beyond that, no, I don't know." (Teacher).

"(About) HIV nothing. What had been done was with clinical doctors, pediatricians (who came to give a talk but it wasn't systematically implemented school-wide)." (Teacher).

Focus group: A focus group was conducted with eight young people (4 males, 4 females) aged 16-22 (mode: 18) who had participated in at least one step of the dance4life program in their schools; an additional person who had not participated as a student but as a workshop coordinator joined. Three were students and graduates of the same school of CABA, three were from two different schools in Claypole, and the other two were from two different schools in Moron both localities within AMBA. Two focus group participants had been a part of dance4life in 2010, three in 2011, and the remaining two in 2013. One of the young people had participated in 2011, 2012, and 2013.

Everyone in the focus group had participated in at least one step (INSPIRE), but the majority had participated in three (INSPIRE, EDUCATE, CELEBRATE) of the four steps. Everyone who had participated in the INSPIRE step said they enjoyed the activities, and could recall the topics covered and the activities conducted. A girl who only participated in the INSPIRE step suggested expanding the topics covered in this step as an opportunity to educate as many students as possible, especially those not participating in the following step.

Everyone agreed that prior to the presence of dance4life in their school, there was very little sexuality education in the schools. While many of the participants said that it was not addressed in any way, others mentioned that the little they had received was “(...) very, very boring. It put you to sleep (...)" (female, 17 years) or "basics, basics, basics" (male, 16 years). Another young person commented: "In my school there were many kids who didn't know much, even though they were already sexually active. At least I learned a lot. Before the workshops, I didn't know too much either" (male, 18 years). As for what they learned in general, there was agreement that it was a "before and after" experience (female, 17 years). For example, regarding their knowledge of HIV testing a young man said: "I thought it was something totally and completely difficult, (that) it was expensive. I thought it was like that, very difficult, only people with money could go get tested" (male, 18 years) and another said: "I was afraid that if someone got tested it was because of something. But no, it's all confidential and all that" (female, 18). They also mentioned learning about sexuality in general, gender, rights, and contraception: "In the school, sex is not addressed. This is an opportunity to start talking about different contraceptive methods a little bit more in schools" (male, 18 years) and another person said "in my case, about contraception methods, but also about HIV" (female, 17 years). With respect to adolescent rights they mentioned: "The right to get tested, to have it be confidential, and to not discriminate against people with HIV" (female, 18), "and that as of 14 years old you can go anywhere, you can get tested without your parents" (male, 18 years). 
Participants discussed about the age of peer leaders and their ability to build trust with the young people, the participation of the YHN in dance4life activities was stated as being positive: "In addition, the way they address it, as she said, it is not boring, it's changing all the time and with different activities. The workshops are not all the same. For example, in each workshop we have a different activity and it is done differently in some groups and this is good" (male, 18) and "I do not know if (an adult leading a workshop) can do it in a fun way, it's just that we're going to approach it in another way. It's like, it's an adult. Even though those who came were adults, they were not as adults as the teachers were" (male, 18 years).

Additionally, all the young people who participated in the focus group said they felt like agents4change, whether they continued to participate in activities with the YHN or not. They stressed the importance of the change that the program generated within them, "because we changed with the project" (female, 17 years) and their ability to become health promoters, "after the talks, I knew what I was talking about, rather than saying just anything and then having others believing it" (female, 18). One participant mentioned that her experience with dance4life inspired her to want to promote change in other organizations where she participated "I was active in a political party close to my home before and I had become very good friends with a coordinator there and I had also told him about this and he was like 'Oh, that's interesting' and he called here (FH) to request a workshop for the young people in the political party. And I felt very important, very excited that this was because of $m e$ " (female, 17 years). Finally, they mentioned feeling empowered to talk with others, "not to be ashamed to talk with others" (female, 17 years).

Almost all agreed that the benefit of the closing step (CELEBRATE), was the possibility to socialize with students from other schools and see the context in which dance4life is embedded:

"It helps to know that it is not just in one school, it is not only in your own city, but there are many more people who care about this issue and it makes you feel like yes, there are more people in a lot of places that are also involved in the same movement. It also helps to know that you're not the only one (...) It even makes you feel more committed, as you see that there are people in other places and so, let's continue helping, let's do it even bigger" (male, 18 years)

\section{Discussions}

The dance4life program has trained over 2,000 agents4change over a period of four years. In the visited schools, the experiences reported were generally positive, even the ones where difficulties arose both during program implementation and in the continuation of the program in the schools. One of the most positive aspects highlighted during the interview had to do with the peer-led component. Although there has been contradictory evidence as to the effectiveness of peer-led interventions, this evaluation has provided some evidence of positive effects on both recipients and providers of educational program, especially with regards to program design and support $[16,18,22]$. Despite this, there is insufficient evidence that the program has impacted the comprehensive approach to sex education in the classrooms and additional follow-up data would be necessary to make long-term inferences. The program evaluated included many of the components required for sexuality education programs, and although few studies have been able to prove biological impact of such educational programs, the findings from this evaluation prove promising $[29,30]$.

Although the sample used for the survey is not representative of the entire national territory, it can be used to compare results with some statistical data at the national and local levels. In the survey sample, the age at first sex was similar to that obtained in a national survey of sexual and reproductive health among 14 to 19 year olds, and also similar to that reported in a study in urban clusters in the country $(15,15.2$ and 15 years, respectively) [8,31]. These results make it impossible to conclude whether dance4life had any effect on delaying sexual initiation [3]. Knowledge of contraceptive methods is also similar in this evaluation than that reported in the previously mentioned studies. Contraceptive use at first sexual intercourse was reported much lower in this evaluation than the data available for the country: only $87 \%$ of female and $58 \%$ of male respondents said they used some method to prevent pregnancy or STIs during first sexual encounter, compared to $90.4 \%$ of females and $87.1 \%$ of males, and $89 \%$ of sexually active youth [9]. Finally, according to estimates by the Statistics and Health Information Bureau and UNFPA Argentina, approximately $16 \%$ of the women between 15 and 19 years old had ever been pregnant resulting in one of the highest adolescent fertility rates of the Latin American region $[3,4,9,10,12]$. Because the sample size in this evaluation is small, comparisons are not deemed appropriate.

Most of the respondents in this evaluation said they knew how to refuse to have sex if they did not want it or if their partners did not agree to use condoms, an indication of overwhelming consensual sex. This finding is similar to that from other sexuality education programs that focus on gender, communication, and power dynamics [29]. Following a set curriculum with constant supervision and training is also a key component of successful sexuality education programs [5,22]. On the other hand, the low proportion of youth who reported using the health system to address their SRH needs could be evidence of difficulties in linkages with the health system, an important aspect of adolescent health programs [32].

This evaluation was the first of its kind in Argentina, and for dance4life in the Americas region. Additionally, this was the first time FH conducted a rigorous evaluation of their peer-led educational programs. There was built capacity resulting from this evaluation, and findings could shape future educational programs. 


\section{Limitations}

There are some limitations to the present evaluation. Lack of comparison groups is a threat to internal validity and making assessment of impact of the intervention difficult. Similarly, selection bias was a concern throughout the evaluation despite efforts at randomizing schools and participants.

Additionally, inconsistency of tools to record information or activities throughout the years of program implementation made data analysis difficult. Lack of baseline data makes conclusions about the impact of the program on knowledge, attitudes and practices difficult. Inferences are made through participant self-reported responses, which also are subject to recall bias. Because of inconsistent and incomplete data regarding the ACTIVATE step, this was excluded from all analysis, while dance4life considers this an important component in their program.

There are other limitations that arose at the time of the evaluation. Despite validation and confirmation with young people about comprehensibility of the survey tool, answers to one question showed lack of understanding of it (question 17, see Annex 2 for the full questionnaire) resulting in lots of missing data. This was taken into consideration while analyzing data, although important information could have been missed because of this.

Qualitative data is inherently non-generalizable, hence not only reflecting the opinion of the majority involved in the program, also not necessarily true of other young people receiving school-based sexuality education. However, the information provided through the interviews and the focus group provides invaluable information about experiences with program implementation which are crucial to understanding the process.

Further analysis would include models that look to assess impact of the program by establishing causal pathways (such as a difference in difference analysis to identify specific gains through the implementation of this program), but this goes beyond the scope of this paper.

\section{Conclusion}

Peer led HIV prevention education programs with multiple components that use classroom interventions, music and dance, and personal involvement in activities as well as consistent training and supervision can have a positive impact in both the young people receiving the intervention and those leading it. Future evaluations that take into consideration baseline data to assess for changes in knowledge, attitudes, and behaviors of young people with relation to HIV and sexuality will shed further light into this.

\section{Acknowledgments}

The authors would like to thank the staff at Fundacion Huesped involved in the development of the study: Virginia Zalazar, Mar Lucas Gómez, Cecilia Valeriano, and Lucas Villalba. They would also like to thank dance4life international for providing funding for the evaluation.

\section{References}

1. UNAIDS (2016) AIDS by the numbers 2016: Ending the AIDS epidemic by 2030 as part of the Sustainable Development Goals, Geneva, Switzerland.

2. Buenos Aires: National Ministry of Health (2016) Directorate of AIDS and STIs, National Ministry of Health. Bulletin on HIV-AIDS in Argentina. Year XIX [Dirección de Sida y ETS, Ministerio de salud de la Nación. Boletín sobre el VIH-sida en la Argentina. Año XIX], Argentina.

3. Buenos Aires: Directorate of health statistics and information (2015) Vital statistics. Basic information - year 2014. [Estadísticas vitales. Información básica - año 2014], Argentina.

4. Binstock G (2016) Adolescent Fertility and Maternity in the Southern Cone: Notes for the construction of a common agenda [Fecundidad y Maternidad Adolescente en el Cono Sur: Apuntes para la construcción de una agenda común]. Buenos Aires: UNFPA, Argentina.

5. World Health Organization (2016) Social determinants of sexual and reproductive health: informing future research and programme implementation. Geneva, Switzerland.

6. Buenos Aires: National Ministry of Health (2015) Directorate of AIDS and STIs, National Ministry of Health. Bulletin on HIV-AIDS and STIs in Argentina. Year XVIII [Dirección de Sida y ETS, Ministerio de salud de la Nación. Boletin sobre el VIH-sida e ITS en la Argentina. Año XVIII], Argentina.

7. Buenos Aires: National Ministry of Health (2013) Directorate of AIDS and STIs, National Ministry of Health. Bulletin on HIV-AIDS and STIs in Argentina. Year XVI [Dirección de Sida y ETS, Ministerio de salud de la Nación. Boletín sobre el VIH-sida e ITS en la Argentina. Año XVI], Argentina.

8. Buenos Aires: National Institute of Statistics and Censuses (2013) National Ministry of Health. Encuesta nacional sobre salud sexual y reproductiva. [National survey on sexual and reproductive health], Argentina.

9. UNICEF Argentina and National Ministry of Health (2016) Situation of the health of adolescents in Argentina [Situación de la salud de los y las adolescentes en la Argentina]. Argentina.

10. Brizuela V, Abalos E, Ramos S, Romero M (2014) El embarazo en la adolescencia. Buenos Aires: Observatorio de Salud Sexual y Reproductiva.

11. UNICEF Argentina (2013) Situation of adolescent pregnancy in Argentina on World Population Day [Situación del embarazo adolescente en Argentina, en el día mundial de la población], Argentina.

12. UNFPA Argentina (2016) Tips para padres preguntables, Argentina.

13. dance4life (2016) Our approach, Netherlands. 
14. van Weert JC, Hermanns SST, Linn AJ, Schouten BC (2011) Dance4life: Evaluating a global HIV and AIDS prevention program for young people using the Pre-Im framework for process evaluation. Int Public Health J 3: 99-110.

15. United Nations (2016) United Nations Millennium Development Goals, Geneva, Switzerland.

16. Haignere CS, Freudenberg N, Silver DR, Maslanka H, Kelley JT (1997) One method for assessing HIV/AIDS peer-education programs. J Adolesc Health 21: $76-9$.

17. Medley A, Kennedy C, O’Reilly K, Sweat M (2009) Effectiveness of Peer Education Interventions for HIV Prevention in Developing Countries: A Systematic Review and Meta-Analysis. AIDS Educ Prev 21: 181-206.

18. Tolli MV (2012) Effectiveness of peer education interventions for HIV prevention, adolescent pregnancy prevention and sexual health promotion for young people: a systematic review of European studies. Health Educ Res 27: 904-13.

19. Milburn K (1995) A critical review of peer education with young people with special reference to sexual health. Health Educ Res 10: 407-20.

20. Fishbein M, Yzer MC (2003) Using theory to design effective health behavior interventions. Commun Theory 13: 164-83.

21. Bandura A (1977) Self-efficacy: Toward a Unifying Theory of Behavior Change. Psychol Rev 84: 191-215.

22. WHO (2009) Promoting adolescent sexual and reproductive health through schools in low income countries: an information brief.

23. Saunders RP, Evans MH, Joshi P (2005) Developing a Process-Evaluation Plan for Assessing Health Promotion Program Implementation: A How-To Guide. Health Promot Pract 6: 134-47.

24. Wilson MG, Goetzel RZ, Ozminkowski RJ, DeJoy DM, Della L, et al. (2007) Using formative research to develop environmental and ecological interventions to address overweight and obesity. Obesity 15: 37-47S.

25. Hsieh HF, Shannon SE (2005) Three Approaches to Qualitative Content Analysis. Qual Health Res 15: 1277-88.

26. Seidman I (2006) Technique Isn’t Everything But It Is A Lot In: Interviewing as qualitative research: A Guide for Researchers in Education and the Social Sciences (3rd Edn) Teachers College, USA.

27. Burnard P, Gill P, Stewart K, Treasure E, Chadwick B (2008) Analysing and presenting qualitative data. BDJ 204: 429-32.

28. Global School-based Student Health Survey (GSHS) (2007) Argentina GSHS Questionnaire. CDC.

29. Haberland N, Rogow D (2015) Sexuality Education: Emerging Trends in Evidence and Practice. J Adolesc Health 56: S15-21.

30. Ivanova O, Pozo KC, Segura ZE, Vega B, Chandra-Mouli V, et al. (2016) Lessons learnt from the CERCA Project, a multicomponent intervention to promote adolescent sexual and reproductive health in three Latin America countries: a qualitative post-hoc evaluation. Eval Program Plann 58 : $98-105$.

31. Wang L, Vázquez M, Ravalli MJ, Durán A (2011) Conocimientos, actitudes y prácticas en VIH y salud sexual y reproductiva (SSR) y uso de tecnologías de la información y la comunicación (TIC) entre adolescentes de Argentina, Fundación Huésped and UNICEF Argentina, Argentina.

32. Kalamar AM, Bayer AM, Hindin MJ (2016) Interventions to Prevent Sexually Transmitted Infections, Including HIV, Among Young People in Low- and Middle-Income Countries: A Systematic Review of the Published and Gray Literature. J Adolesc Health 59: S22-31.

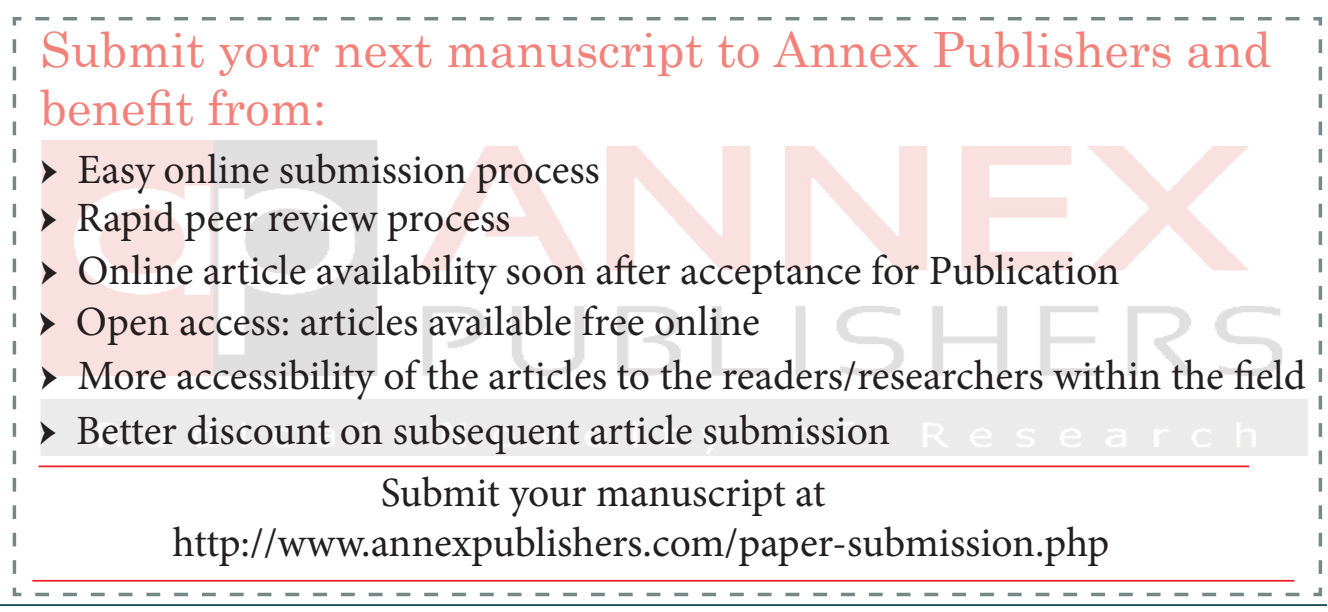

